\title{
REVIEWS
}

\section{Vicky Googasian}

\section{Reading in the Zoopolis}

Aaron M. Moe. Zoopoetics: Animals and the Making of Poetry. Lanham, MD: Lexington Books, 2014. 150 pp. $\$ 80$ (hb).

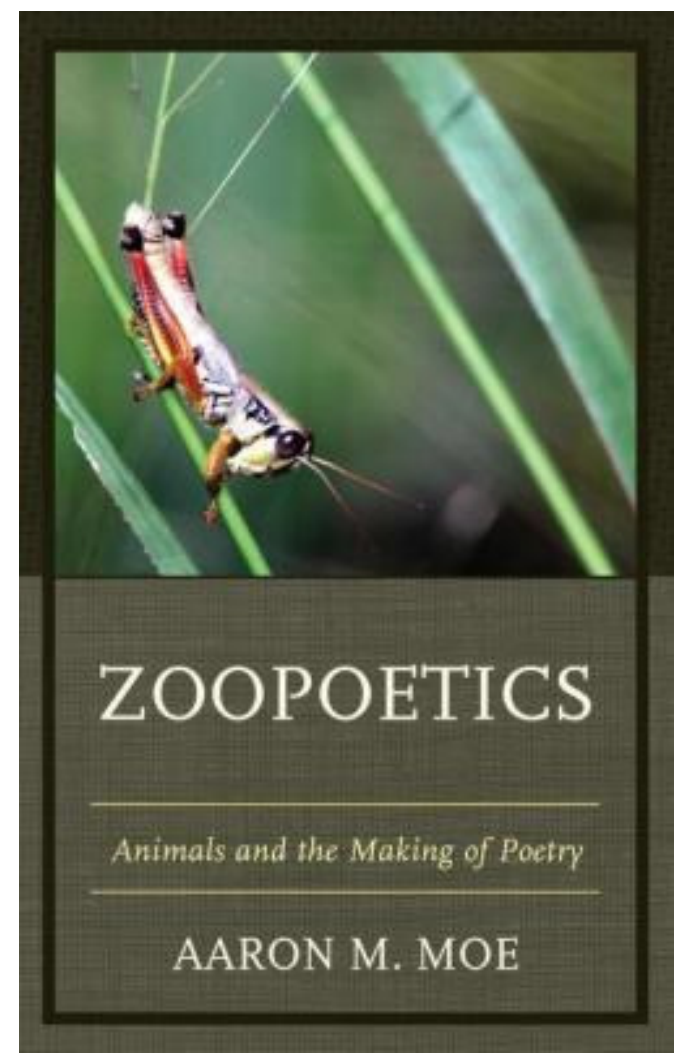

I began reading Aaron Moe's Zoopoetics during an afternoon at the beach. It was a blustery northern California day, and I took the opportunity between the introduction and the first chapter to fly a kite with some friends. I was hard at work trying to keep the kite aloft between the ocean on one side and the cliffs on the other, when a red tailed hawk suddenly drifted into view over the top of the bluffs. I do not think it had the slightest interest in the kite - but it was clear from my position on the ground that the 
hawk was the original whose effortless motion the kite was built to copy. I couldn't hold both fliers in focus at the same time; I had to land the kite and watch the hawk instead.

Moe's book is about precisely this kind of inter-species mimesis. Zoopoetics interrogates the manifold ways humans make things - kites or poems - in imitation of other animals, their movements, bodies, and gestures. As he puts it, "Zoopoetics is the process of discovering innovative breakthroughs in form through an attentiveness to another species' bodily poiesis" (10). Moe tracks zoopoetic tendencies through the work of four major American poets: Walt Whitman, e.e. cummings, W.S. Merwin, and Brenda Hillman. His quartet divides nicely down the middle: on the one hand, Whitman and cummings establishing a sort of origin story for the role of zoopoetics in American formal experimentation: Moe credits multi-species poiesis for Whitman's long sentences and cummings eclectic punctuation, to name just a few examples. At the other end of the American poetic tradition Moe sees Merwin and Hillman as developing a slightly different breed of zoopoetics, this one characterized by its response to ecological crisis and mass extinction in the late 20th and early 21st century. This is the zoopoetics of animal absence. Though Moe does trace some lines of influence among his chosen poets - he devotes some space in particular to highlighting the surprising archival relationship between cummings and Whitman - his project is not primarily to develop a literary-historical arc. Rather, the strength of Moe's work lies in its provocative, creative, and frequently surprising close readings, and in the way zoopoetics reanimates poems with the flickering shadows of animal bodies.

I would argue that Moe's book contains a second, unspoken thesis, one more to do with reading practice than with the making of poems per se. Over and over again, zoopoetics insists that the best way to read an animal poem (at least one produced in the attentive disposition Moe sees as prerequisite for poiesis in the first place) is to hold both poem and animal in focus at the same time. A good example is Moe's reading of cummings' "(im)c-a-t(mo)," which takes its lead from a letter cummings wrote to his Japanese translator describing the behavior of a falling cat. Moe brings to bear his own knowledge of cat bodies and motions to track the twirling trajectory of the cat's fall and recovery through the poem's layout, typography, and punctuation. The reading depends on some attention to cats and their doings: both their "marvelous ability to leap off of air" and their propensity to "save face" (76). The virtuosity and knowingness of this reading does justice to persistent demands within ecocriticism for rejuvenated critical attention to the natural world. One might place Moe alongside John Rowlett,

Humanimalia: a journal of human/animal interface studies

Volume 6, Number 1 (Fall 2014) 
who wrote in the ecocriticism special issue of New Literary History about the need for literary critics to become practicing ornithologists. Rowlett suggests that readings of bird poems can be significantly enriched by knowing something about birds - in his example, it's important that Yeats' falcon is a gyrfalcon, a species known for not minding human handlers, thus the widening gyre. Moe's readings frequently follow a similar arc, and his own wide-ranging interest in animal behavior is showcased in the interludes between chapters, brief vignettes that recount engaged encounters between humans and other animals. Ultimately, if there's a critical imperative hidden in Zoopoetics, it's the insistence that we allow poetry and animal bodies to overlay one another in translucent palimpsests of meaning - we can't read poems without reading animals first.

But what is truly refreshing about Moe's readings is that they actually suggest poetic projects in delightful surplus of the responsible ethic of attentiveness Moe champions in his introduction. I like Moe's etymological idea of attentiveness as "a stretching toward something else" (24), but I sometimes wonder if this word is accurate for the myriad ways species actually meet. There's something eye-opening, for example, about Randy Malamud's suggestion "that we might at least consider the desirability of knowing animals, in the future, less than we have done in the past and present - to spare them the fate that is consequent upon our knowing them increasingly intently ... knowing them to death" (38-9). Despite its emphasis on attentiveness, I think Moe's zoopoetics achieves this tricky epistemic balance quite nicely. Zoopoetics might encapsulate what nonhumans can teach us about making and reading poetry, but the poetry in question hardly fixes animals as transparent objects for the human gaze. Consider Moe's reading of Whitman's "A Noiseless Patient Spider," which begins by establishing the poem's iconicity, the way its soft sounds and long lines mimic the spider's own creative practice. Reading the poem this way requires that we pay attention to the lives of spiders and the work of web-weaving, but Moe does not end by treating Whitman's poetic as an exercise in natural history. It is, after all, a poem about the most fragile of connective tissues between self and other, and Moe's consideration of the spider, like Whitman's, leaves him to note that "one reels at the abyss" between human and arachnid. Moe gets here via Derrida, but this moment struck me as an example of the kind of astonishment Cora Diamond describes in her well known essay on "The Difficulty of Reality and the Difficulty of Philosophy" as the natural product of our 
exposure to the difficult realities of otherness. One particular accomplishment of Moe's book is the demonstration that we can arrive at this astonishment via close reading: that close reading does not necessarily bring us close to other animals, but rather quite accurately captures through its practice the whole range of startled, bewildered, confused, and astonished responses we frequently express toward other species.

One can track this complexity of response through Moe's analysis from Whitman forward. It's there in his reading of cummings's "t,h;r:u;s,h;e:s" when Moe discovers in the line breaks not a solidly reassuring poeisis but "the state of not quite-ness," a dormant way of being alive. It's there in particular in the chapters on Merwin and Hillman, both poets of animal absence, from whom Moe shows us how to read for the places where zoopoetics do not function, as when the "heaving movement" of the whale drops out of Merwin's "For a Coming Extinction," and leaves us with only its "bewildering absence" (100).

In these last two chapters, the potential of zoopoetics to speak to species extinction becomes explicit - we see that loss of biological life also robs us of possibilities for poetic form. If zoopoetics can be politically engaged, this is the avenue by which such engagement occurs. For this reason, Brenda Hillman's Practical Water is an inspired choice as the topic of Moe's closing chapter. In his search for traces of the "multispecies polis" in Hillman's work, Moe demonstrates how close reading, seemingly the most apolitical of devices in the critic's arsenal, can be used to deepen and color the zoopolitical valences of a work of poetry. Moe puts Hillman in conversation with Percy Shelley, who saw the poets' unacknowledged legislation operating by means of imaginative sympathy, or rather, "imagination enlarged by a sympathy" (qtd in Moe 131). Moe suggests that Hillman's sympathy "expands further" than Shelley's, "due to her attentiveness toward and empathy with the many animals facing extinction" (132). This claim quietly proposes an intriguing possibility: that in zoopoetics we find a vehicle for a difficult literary task, namely, the invocation of sympathy not for an individual, but for an entire species. For, after all, Moe's zoopoetics is about the lives and bodies of species, not individual animals. In this sense, zoopoetics is a poetics for the 21st century, the age of mass extinctions, in which we desperately need a literature capable of cultivating impossible kinds of sympathy. Zoopoetics argues that the sympathetic imagination can use poetic form to expand both the scope of the human perspective and to transcend the confines of the lyric $I$.

Humanimalia: a journal of human/animal interface studies

Volume 6, Number 1 (Fall 2014) 
Apart from these epiphanies, Moe's book will best suit those interested in the pleasures and possibilities of reading poetry, not those who want to use poetry as an entry point into the theoretical discourses of animal studies or posthumanism. Moe does have some favorite theorists, namely Donna Haraway and Paul Shepard, whom he uses to situate his reading practices within the burgeoning tradition of posthumanist thought. But Zoopoetics is not as much interested in speaking back to or expanding this tradition as it is in revitalizing the ways we read and write poems. This is a book not about theory but about multispecies praxis, and as its Aristotelian argument suggests, its most thrilling contribution will be its propensity to inspire mimesis. One wishes, upon finishing Zoopoetics, to learn to imitate Aaron Moe: to read with newly renewed consciousness of the animal lives and bodies that already dwell in the poetic canon we know and love.

\section{Works Cited}

Diamond, Cora. "The Difficulty of Reality and The Difficulty of Philosophy." Philosophy $\mathcal{E}$ Animal Life. New York: Columbia UP, 2008. 43-89.

Malamud, Randy. Poetic Animals and Animal Souls. New York: Palgrave MacMillan, 2003.

Rowlett, John. “Ornithological Knowledge and Literary Understanding." New Literary History 30.3 (Summer 1999): 625-47. 